\title{
LA TOMA DE PARTIDO DE ALFONSO REYES
}

¿Qué significa hoy Alfonso Reyes? Si se exceptúa a los (no muy numerosos) especialistas, el nombre de Reyes suele evocar al escritor por antonomasia, ensalzado pero apenas leído, el monumento aislado en la reverencia, a quien rodean, en mezcla indisoluble, homenajes justos y desistimientos de lectura, al amparo del mausoleo de las obras completas. Y estas celebraciones por fe y no por demostración no son fáciles de explicar si se toma en cuenta que, en su combinación de sabiduría y amenidad, Reyes es absolutamente legible (aun descontando el público mínimo, los escasos frecuentadores de ensayo literario y poesía).

A cambio de la lectura escasa, la abundancia de honores. Desde muy joven, a Reyes se le admira por su erudición, su claridad mental, su labor infatigable. El clímax del reconocimiento se da en los años cincuenta, cuando se proclama: "Sin don Alfonso, la literatura mexicana sería media literatura", y se añade con brío: "Reyes es la versión mexicana de la cultura de Occidente". Esta consagración en vida se acompaña de los dicterios de quienes - sin leerlo tampoco- cobijan su malevolencia en la "frase ingeniosa" de entonces: "En tierra de ciegos, el tuerto es Reyes". Leída de manera fragmentaria, vuelta (paradójicamente) inaccesible gracias a la rotunda accesibilidad de las ediciones del Fondo de Cultura Económica, la obra de Reyes llega a recibir el dictamen adverso de Julio Cortäzar: "Erasmo mexicano, hermano viejo, Alfonso Reyes, muerto de veras, oh señor de las letras, en tu tan muerto tiempo".

Entre la apoteosis y la cauda de epitafios implícitos. Y surgen las preguntas: ¿por qué la obra de un gran escritor resulta entidad tan reverenciada como poco concurrida? ¿Por qué en las décadas últimas, casi únicamente las citas incesantes de Borges proclaman la vigencia de Reyes? ¿Por qué suelen ser inconvincentes 
las antologías de su trabajo? ¿Por qué aún se insiste en hacer de Reyes un "marginado del siglo", quien, para mejor resistir el presente, vivificó la erudición y quiso hacer de la literatura su único "tiempo histórico"?

Sostengo precisamente lo opuesto: Reyes no fue " apóstol del distanciamiento". Él se trazó un proyecto muy preciso, la utopía personal y colectiva tal vez dividible en tres etapas: la amistad como formación espiritual a través del diálogo (el trato intelectual con Pedro Henríquez Ureña); la experiencia de grupo como propuesta generacional de avance (su pertenencia al Ateneo de la Juventud), y lo más prolongado: el discurrir del escritor genuinamente convencido, aunque a veces lo exprese de modo retórico, de la vitalidad del ideal humanista, el gran horizonte formativo de la nación y los individuos.

\section{LA AMISTAD COMO PROYECTO COMUNITARIO}

A principios de siglo en México, ¿cómo desaprovechar ostensiblemente la condición de hijo del general Bernardo Reyes, el aspirante a la Presidencia que ha sido secretario de Guerra y gobernador de Nuevo León, uno de los hombres menos débiles de la República al mando de un solo Hombre Fuerte? Reyes, jovende-brillante-porvenir en el porfiriato, desdeña el típico esquema de ascenso, y no quiere ser el abogado solemne que, por pausas, arribe a un ministerio. A él, desde el principio, sólo le importa vivir a fondo la literatura y el proceso intelectual, y con tal de ejercer su vocación al extremo, escribe y piensa en esa etapa, como si estuviera en otro lugar, fuera del boato, la autocomplacencia, la adulación cortesana, la cursilería. El "otro lugar" es el del arte y las humanidades, que Reyes habita con disciplina férrea.

Para este lector nato, convencido de leer-para-vivir, es fundamental el encuentro con Pedro Henríquez Ureña. En 1906, el dominicano Henríquez Ureña, hijo de una poetisa notable y de quien sería presidente de la República Dominicana, es un fenómeno intelectual. Lector incansable en varios idiomas, obsesionado por integrar la tradición humanista y la modernidad, apóstol del aprendizaje y de la enseñanza, Henríquez Ureña representa para Reyes, cinco años más joven, el maestro, el condiscípulo, el amigo perfecto que comprende, exige, regaña, estimula. Del primer tomo de su epistolario se desprende un cuadro: la amistad (la formación conjunta) ve en la cultura al interminable proceso asocia- 
tivo que le da sentido a la vida cotidiana. El 15 de septiembre de 1907 escribe Reyes desde Chapala:

Poco a poco los niños y las mujeres fueron llegando a llenar en el lago sus cántaros de barro y yo, sin pose de erudito, me acordé de aquel pasaje en que Werther ayuda a una campesina a cargar su cántaro rústico... ${ }^{1}$

Todo exige una referencia clásica, todo es libresco y todo es vital, y un intelectual joven no tiene zonas de complacencia. Reyes, que adora a su padre, le confía a Henríquez Ureña (14 de enero de 1908):

El señor general don Bernardo Reyes resuelve todo con mandatos militares y el otro día, discutiendo sobre asuntos literarios, le hice ver que ha adquirido el vicio de maltratar autores que no ha leído. Él se disculpa arguyendo que su trabajo de gobernador no le da tiempo para eso.

Y 15 días después, es más preciso:

Me da tristeza ver que ya no puedo conversar con él [con don Bernardo]. Su favorito en poesía es Santos Chocano, y en filosofía (?) Roosevelt. Está por llamarles ideólogos a los pensadores. Para él sólo vale la acción: para él el Arte es "un instrumento". El otro día me acusó de estrechez de criterio porque no soporté que me hablara de Juan de Dios Peza. En fin, lo que yo me temía: ya no estoy dentro de casa.

Reyes y Henríquez Ureña quieren consolidar y ampliar los 'placeres de la lectura, de la divulgación, del estudio, del acto creativo. Sólo así estarán dentro de casa. Y urge, usando los ejemplos personales, oponerse a los fatalismos del medio anti-intelectual, haciendo que la literatura clarifique la existencia. Ellos ejercen la continuidad vocacional en un medio de frustraciones, y desean rescatar al humanismo de la erudición mecánica de los conservadores y de la incomprensión sectaria de los revolucionarios. Sus ideales son transparentes: la fuerza integradora de la cultura, el lector como el ciudadano ideal, la universalidad del conocimiento que es el acceso a las realidades profundas.

${ }^{1}$ Alfonso Reyes-Pedro HenRíuez URENA, Correspondencia 1907-1914, ed. José Luis Martínez, FCE, México, 1986. 
"Para mí - escribe Henríquez Ureña - una intimidad ha de comenzar en el acuerdo intelectual". Y esto lo dice en 1907, en un continente donde los dictadores se dejan adular por quienes anhelan el patrocinio de los dictadores, y en donde la poesía concentra casi todo el anhelo disponible de rigor. La fe en el diálogo intelectual, en la moral que cada texto segrega, en la disciplina que ahuyentará la improvisación, son fragmentos del sueño cultural de Reyes y Henríquez Ureña. Ellos no se sienten paladines o caudillos, y se limitan a proponer (eso sí, de modo exhaustivo) el trato simultáneo de la poesía, la ficción, la historia, la mitología, el pensamiento clásico.

¿Cómo cristalizar el temperamento civilizado entre las imposiciones de la barbarie que es sinónimo de la condición mexicana o latinoamericana? En primer lugar, y sin así decirlo, se califica a la política de interrupción de la vida normal. En segundo lugar, se pone a prueba, a través de la sistemática comparación de culturas, la calidad del temperamento civilizado. En tercer lugar, se extrema la pasión por la forma que es respeto a la perfección de las ideas. Y en cuarto lugar Reyes y Henríquez Ureña viven la certeza múltiple que se petrificará en el lugar común: el arte formal es o puede ser radical, y de esto depende en buena parte la disolución de los estereotipos y los prejuicios sociales; la sensiblería y la demagogia falsifican la experiencia real; quien defiende, creativamente, el lenguaje del pueblo proporciona elementos fundamentales para ir a fondo en lo que se vive; a la identidad de belleza y verdad no se puede llegar fiado sólo en los mitos.

En 1914 Henríquez Ureña escribe desde La Habana: " $\mathrm{Me}$ he convencido, con tristeza, de que soy superior en la vida a lo que soy escribiendo. Tengo que cambiar, ya sabes que me lo propuse". . Nada de igualar con la vida el pensamiento. Sólo hay una meta significativa: la realización de obras maestras. De esta meta agobiante se desprende la comprensión unificada de la creación y de la crítica, de la investigación y de la divulgación.

\section{LA UTOPÍA DEL GRUPO}

En 1908, en la ciudad de México, el Ateneo de la Juventud es el intento más brillante de autonomía frente al régimen de Porfirio Díaz. Esto se inicia en la elección de temas y estilos literarios y en la celebración del humanismo. Como muchos otros proyectos intelectuales del siglo, de Bloomsbury a Contemporáneos, de Sur 
a Orígenes, el del Ateneo exalta el "banquete platónico" como el paradigma del diálogo, y define el sitio central de las ideas como rechazo del mundo circundante. Una es la encomienda: exceptuarse del atraso, salvarse de la mediocridad intelectual que es el destino en los países periféricos.

¿Quiénes son los ateneístas? Reyes, Henríquez Ureña, Vasconcelos, Martín L. Guzmán, Jesús T. Acevedo, Torri, Antonio Caso, Alfonso Cravioto, Ricardo Robelo. Son hijos de la clase media porfiriana, convencidos por situación y formación'de su natural pertenencia a la élite del poder, y de su elogiable inmunidad ante la barbarie. Es tan arduo ser intelectual en tierra de indios y caciques, de burgueses analfabetas y declamadores del Espíritu, que es preciso hacer de la posesión del conocimiento una certeza victoriosa: lo que a nosotros preocupa le atañe a muy pocos; lo que a nosotros nos incumbe es lo único importante.

En las postrimerías del porfiriato, el Ateneo de la Juventud es la promesa: una cultura al orden del día, según se vive en Londres o París. Es tal la excepcionalidad que años después Reyes y Vasconcelos verán en este desempeño generacional el antecedente cultural directo de la revolución. Esto no me resulta muy comprobable. El Ateneo de la Juventud se presenta en público con una manifestación adversa al periodista Manuel Caballero que quiso usar el nombre de la revista $\mathrm{Azul}$, de Manuel Gutiérrez Nájera. Los ateneístas protestan y el establishment los bendice. Así lo cuenta don Alfonso:

Por 1907, un oscuro aficionado quiso resucitar la Revista Azul de Gutiérrez Nájera, para atacar precisamente las libertades de la poesía que proceden de Gutiérrez Nájera. No lo consentimos. El reto era franco, y lo aceptamos. Alzamos por las calles la bandera del arte libre. Trajimos bandas de música. Congregamos en la Alameda a la gente universitaria; los estudiantes acudieron en masa. Se dijeron versos y arengas desde el kiosko público. Por primera vez se vio desfilar a una juventud clamando por los fueros de la belleza, y dispuesta a defenderla hasta con los puños. Ridiculizamos al mentecato que quería combatirnos, y enterramos con él a varias momias que andaban por ahí haciendo figura de hombres. Por la noche, en una velada, Urueta nos prestó sus mejores dardos y nos llamó "buenos hijos de Grecia". La revista Azul pudo continuar su sueño inviolado. No nos dejamos arrebatar la enseña, y la gente aprendió a respetarnos ${ }^{2}$.

2 Alfonso Reyes, "Pasado inmediato", AROC, t. 12, pp. 207-208. 
Éste, el texto más severo de Reyes (Pasado inmediato) por otra parte, no informa de disidencia política, ni siquiera de mínimas heterodoxias. El Ateneo de la Juventud encauzó su crítica dentro del orden, y su gran innovación fue la exigencia de rigor, no la resistencia al poder. Así, su otro gran acto es en memoria de Gabino Barreda, el implantador del positivismo. El Imparcial se sorprende "ante aquellos nietos descarriados del positivismo que, sin embargo, confesaban su solidaridad con la obra liberal de Barreda". Y Reyes añade: "En el orden teórico no es inexacto decir que allí amanecía la Revolución" . La afirmación, un tanto controvertible, ignora por ejemplo la acumulación teórica y la condición rebelde de los anarco-sindicalistas de Ricardo Flores Magón. Sin embargo, Reyes cree estar diciendo la verdad. Él no cree en revolución alguna, ni le interesa. Lo suyo es la armonía civil y la construcción de su propia obra. A eso se dedica y eso puede hacer, y para él revolución es vocablo despojado de su connotación violenta, y casi sinónimo de institucionalidad.

Los ateneístas serán mitificadores formidables de su acción colectiva, con la excepción de Vasconcelos, que en sus memorias no le atribuye demasiado valor al grupo y se concentra en la mitificación individual. Si elogia el esfuerzo intelectual, es con tal de hallarlo mediocre, sin alma:

Todos mis compañeros escribían a base de citas y entrecomillados. Los libros del propio Caso dan fe de esta tendencia erudita. Los literatos de mi grupo no se decidían a escribir, por ejemplo, una novela; se gastaban en comentarios y juicios de la obra ajena a lo Henríquez Ureña, que les hacía de maestro ${ }^{3}$.

Los otros son mucho más generosos. Por ejemplo, Martín Luis Guzmán alaba el afán de especialización del grupo, su desdén por el "genio improvisado", su método de trabajo:

Semanariamente nos reuníamos en la biblioteca de Caso, donde leíamos y comentábamos libros fundamentales. Éramos grandísimos lectores, grandes conversadores: nos comunicábamos impresiones y analizábamos nuestras ideas. Todo nos preocupaba. Éramos muy serios $^{4}$.

${ }^{3}$ José Vasconcelos, Ulises criollo, Ed. Botas, México, 1935, p. 272.

4 Emmanuel Carballo, "Martín Luis Guzmán", en Protagonistas de la literatura mexicana, México, SEP, 1986, p. 78. 
Si se pone entre paréntesis la tendencia a rescatar el pasado personal como hazaña nacional resulta innegable la gran aportación del Ateneo de la Juventud. No los únicos, pero sí los involucrados en el intento más significativo, los ateneístas se dirigen a versiones rigurosas y sólidas de la cultura occidental. Obligadamente librescos, entusiastas del ideal del simposio platónico, preservan en sus años de grupo la utopía del conocimiento y, algo fundamental, reivindican el humanismo a través del amor a los textos griegos, del redescubrimiento de España y el descubrimiento de Inglaterra, de la insistencia en "la siempre amable y amada Francia'".

"Y El QUe QUiera SABER QUiÉN SOY..."

Al sobrevivir la revolución, Reyes se hace a un lado. No tiene manera (personal, familiar o intelectual) de entenderla en sus términos. En 1911, le escribe a Henríquez Ureña: "Estamos solos Caso y yo, nos parece que se ha derrumbado el mundo y los dos nos hemos hallado sentados en la cúspide de la pirámide de escombros'. Si algunos de sus compañeros intervienen en política (Caso apoya la reelección de Díaz, Vasconcelos y Guzmán son maderistas), Reyes se aferra a su ideal literario, al que le entrega todo el tiempo disponible.

El proceso de Reyes es desigual o contradictorio. Pretende por un tiempo seguir como si la revolución no ocurriese, inmerso en lecturas y espectáculos y conferencias. En abril de 1911 le escribe a Henríquez Ureña comunicándole su proyecto de hablar sobre el teatro de la Monja Hrostvitha. Y el 6 de mayo de 1911, su confesión es casi desesperada:

Estoy triste: me aflige mucho la situación de mi padre y veo que se desvanece la esperanza que tenía, que he tenido desde hace mucho, de vivir a su lado cómoda y felizmente, siquiera dos años. No sé ya lo que será de nosotros. Me parece que voy a tener que perder mucho tiempo de mi vida en resolver cosas inferiores y que volveré a sacar la cabeza dentro de varios años. Quisiera salirme de México para siempre: aquí corro riesgo de hacer lo que no debe ser el objeto de mi vida. Como no tengo entusiasmos juveniles por las cosas épicas y políticas, ni la intervención yankee, ni los conflictos me seducen gran cosa. Preferiría escribir y leer en paz y con desahogo.

El otro heroísmo: la persistencia, la defensa de la vocación, 
el resguardo del objetivo de una vida. Reyes, que se conoce bien, tiene razón en lo que a él respecta, y sin embargo lo entusiasma la creación de la Universidad Popular, cuando "un secreto instinto nos dice que pasó la hora del Ateneo":

El cambio operado a la caída del régimen nos permitía la acción en otros medios. El 13 de diciembre de 1912, fundamos la Universidad Popular, escuadra volante que iba a buscar al pueblo en sus talleres y en sus centros, para llevar, a quienes no podían costearse estudios superiores ni tenían tiempo de concurrir a las escuelas, aquellos conocimientos ya indispensables que no cabían, sin embargo en los programas de las primarias 5 .

El compromiso dura poco. En 1913, cimbran a Reyes el cuartelazo de Victoriano Huerta, los asesinatos de Madero y Pino Suárez, y la muerte trágica de su padre. Hoy, desprestigiadas al máximo las condenas del realismo social ("Reyes, extranjerizante, elitista"), es la piedad filial la hipótesis más favorecida para explicarse el alejamiento de Reyes del juicio o de la opinión políticos. De diversas maneras, se asume que para don Alfonso la historia cesó el 9 de febrero de 1913, en el instante en que el general Bernardo Reyes muere acribillado en su ataque suicida a Palacio Nacional. El mismo don Alfonso algo similar admite en su bellísima Oración del 9 de febrero:

Aquí [ese día] morí yo y volví a nacer, y el que quiera saber quién soy que se lo pregunte a los hados de febrero. Todo lo que salga de mí, en bien o en mal, será imputable a ese amargo día ${ }^{6}$.

Sin menospreciar el argumento, no es muy verificable en el proceso de Alfonso Reyes. A él le importaba en demasía la figura paterna, pero su actitud básica estaba ya definida antes del 9 de febrero. Se había propuesto ser un escritor, alguien marginal a la historia, y la desaparición de su padre no modificó su elección. Y lo que sigue, lo comprueba. Por dignidad, rechaza de inmediato el puesto de secretario de Huerta, y por ansiedad, acepta en 1913 un puesto muy menor en París. En sus cartas a Henríquez Ureña, Reyes evidencia la voluntad de pertenecer a otra realidad, lo que incluso lo conduce a la autoflagelación psíquica. Escribe el 6 de noviembre de 1913:

5 "Pasado inmediato", p. 213.

${ }^{6}$ Alfonso Reyes, Oración del 9 de febrero, Era, México, 1963, p. 22. 
Y París pasa delante de mis ojos sin dejarme la menor enseñanza porque los conflictos espirituales son demasiado vivos hoy para mí, y me borran la relativa existencia del mundo exterior. Tenía que ser: a mí todo me sucede en condiciones contrarias, todo me resulta al revés. Ser crítico es no ser hombre. Ser creador de la vida, es estar fuera de ella. (No se puede repicar y andar en procesión.)

Con perseverancia, Reyes quiso ocultar (y quizás en ocasiones ocultarse), sus ideas profundas, guiado por aquellos "pactos con la posteridad", que le indujeron a facilitarle la tarea a sus biógrafos con su estrepitosa Historia documental de mis libros. Pero en su generación, es Reyes quien con más ahínco acepta la tesis del Escritor como-Hombre-Nuevo que acompaña y le da voz (forma) a la Nación Nueva. Y esto es un homenaje directo e indirecto a la revolución mexicana, a la que asimila de distintas maneras. No hay entre los escritores partidarios de la revolución un plan de reconstrucción moral tan nítido como el de Reyes. Él lo afirmó sin que los demás le creyeran del todo: "Entre nosotros no hay, ni puede haber torre de marfil . . [la propia es] el trabajo intelectual como un servicio público y como un deber civilizador'.

Reyes asume de manera sistemática el sentido misional de los ateneístas, promovido con intención épica por Vasconcelos en sus años de Secretario de Educación Pública. Sólo quien se prepara con rigor, divulgará con amenidad. Esta línea de conducta explica el carácter fragmentario de gran parte de la obra de Reyes, integrada por recopilaciones. Escribe para los periódicos, porque allí, y no en el territorio mucho más restringido del libro (hasta fechas muy recientes, un privilegio forzado de las élites), los intelectuales pueden cumplir en un país donde se lee poco, con su servicio público y deber civilizador. $\mathrm{Y}$ también por lo mismo, Reyes cree en el libro, el objeto que preserva y solidifica el impulso del pensamiento.

\section{LA UTOPÍA INDIVIDUAL}

A lo largo de su estancia en París, en Madrid, en Río de Janeiro, en Buenos Aires, Alfonso Reyes afina el sentido de su trabajo. Si la literatura explora y encumbra el proceso civilizatorio, no hay tarea más alta que la creación, la difusión y el disfrute de las obras maestras del espíritu, que la enseñanza y la actualización de los clásicos, que la ubicación de la armonía que eliminará la intole- 
rancia. Cuando él escribe: "Todo lo sabemos entre todos", pregona su punto de vista: nadie posee las claves enteras del saber, todos somos indispensables.

En 1938, publica uno de sus textos fundamentales, Homilia por la cultura ${ }^{7}$, alegato que es protesta contra las aberraciones de los especialistas. Allí Reyes pide equilibrar el tiempo para la acción y el tiempo para la contemplación; confía irónica y piadosamente en que un vistazo diario al reino de la cultura nos libertará de accidentes y desgracias; define a la cultura como función unificadora; rechaza la división de ciencia y humanismo; advierte el carácter heroico de la sed de conocimiento, en un medio que no lo alienta; se pone -en su rápida visión de Brasil- como modesto ejemplo de "cómo un simple aficionado a las letras puede hallar también sus alimentos en los cuadros estadísticos, las listas de precios y los conocimientos de embarque", y elogia a la imaginación, electricidad esencial del espíritu que todo lo entiende y vivifica.

El respeto al proyecto civilizador se transparenta a lo largo de la obra de Reyes, incluso en momentos tan fallidos como la Cartilla moral, la caída en el paternalismo. A tal punto le interesa la encomienda de ilustrar, de proporcionar resúmenes útiles y amenos de la historia y la literatura que centra la moral del escritor en el diálogo con el lector. Anti-autoritario en la forma, a Reyes el deber civil lo obliga a intensificar la claridad expresiva, porque la oscuridad es signo del desorden mental que es barbarie. Aquí se manifiesta la razón profunda ("mi único anhelo") de Reyes: la lealtad a la vocación, que persiste en un medio que no lo consiente, colmado de los "enemigos de la promesa", de las dispersiones que Ciril Conolly catalogó: la burocracia, el periodismo, la ideología, la política.

Ante la política y, en buen grado, ante la intensidad literaria, Reyes fue un descreído, un escéptico y por eso lo increparon los realista-socialistas, como lo hubiesen mal interpretado los surrealistas. Pero, y en esto fue extraordinario, Reyes vivió casi antes que nadie la secularización como atmósfera inevitable, y mantuvo esa actitud el resto de su vida, a diferencia, por ejemplo, de Vasconcelos, que va del catolicismo a la religión educativa, y de allí, con agresividad rencorosa, a la ultraderecha católica. Reyes es definitivamente laico, y al renunciar sin estruendo a los "sobornos del cielo", se adapta sin problemas a las tareas del siglo.

${ }^{7}$ Alfonso Reyes, Homilía por la cultura, AROC, t. 11, pp. 204-221. 
En la versión de Reyes, ser laico es vivir cordialmente la cultura, sin premuras y sin pausas; ser laico es depositar en el saber la redención histórica de las naciones; ser laico es comprender los puntos de vista, las demandas, las búsquedas formales, los juicios ajenos. Escribe a Emmanuel Carballo el 13 de febrero de 1959:

$Y$ voy a revelarle un secreto, querido Emmanuel, y entienda usted bien que es secreto y no se lo cuente más que a sus íntimos: para quien se ha pasado la vida estudiando las principales literaturas a través de los siglos, lo más difícil es no entender en el sentido de no aceptar; pues ése ha visto ir y venir los cambios de asuntos y de maneras, y sabe que todos esos cambios responden - hasta cuando son más inusitados y extravagantes - a una íntima necesidad ${ }^{8}$.

\section{LA FUNCIÓN UNIFICADORA DE LA CULTURA}

Reyes, tan opuesto a condicionamientos y normas, abundó en indicaciones sobre lo constructivo y lo positivo. Él, aparentemente inmune a la historia de su tiempo, analizó sin cesar - aunque siempre en tono de aparente digresión- las condiciones del escritor y la forja del público, resumiendo oblicuamente su idea del proceso nacional. Así, afirma en Última Tule:

El escritor tiene aquí mayor vinculación social, desempeña generalmente varios oficios, raro es que logre ser un escritor puro, es casi siempre un escritor "más" otra cosa u otras cosas. Tal situación ofrece ventajas y desventajas. Las desventajas: llamada a la acción, la inteligencia descubre que el orden de la acción es el orden de la transacción, y en esto hay sufrimiento. Estorbada por las continuas urgencias, la producción intelectual es esporádica, la mente anda distraída 9 .

Reyes se propuso ganar tiempo, y, sobre todo, seguridades psicológicas y culturales para un escritor, él mismo, y ésta fue su manera modesta y soberbia de ganarle espacio a la civilización. Con todo, el suyo no fue proyecto individual. Quien careció de temperamento ostensiblemente religioso, y se mantuvo alejado de la fe tradicional y de la mitificación de la Patria y el Pueblo, vivió hasta el extremo la creencia en el saber colectivo, y esto lo impul-

${ }^{8}$ E. Carballo, “Alfonso Reyes", en op. cit., p. 150.

9 "Última Tule", $A R O C$, t. 11, p. 85. 
só a recrear culturas, temperamentos artísticos, civilizaciones. En un medio cerradamente anti-intelectual, de minorías semi-ilustradas y mayorías analfabetas, que coinciden en una creencia (los ilustrados son apologistas explícitos o implícitos de la perversidad), Reyes deseó encarnar al hombre de letras universal, que le agrega a la nación dimensiones universales. Por eso, con insistencia, trazó el sueño civil donde la armonía (las leyes de la estética) engendrará la formación moral.

Así enunciado, el proyecto es por lo menos confuso. Pero Reyes, un liberal que no se declaraba tal por miedo a las clasificaciones, amplió en sus mensajes la esencia de los ideales juveniles, coincidentes en varios puntos con los que Vasconcelos deseó implantar en la Secretaría de Educación Pública. De manera literal, Reyes confió en el poder de los ideales clásicos. Si Vasconcelos repartió libros de Homero, Dante, Goethe, Tolstoi, Plotino o Plutarco, para darle al Estado la fundamentación humanista que mostrara su nivel internacional, Reyes confió en la correa transmisora de la latinidad y de la cultura griega. Sin eso no habría cultura, porque las raíces iluminan el desenvolvimiento. Si la inteligencia fabrica ciudades, la cultura nutrida por Grecia y Roma es la vía del desenvolvimiento confiable.

No olvidéis que un universitario mexicano de mis años sabe ya lo que es cruzar una ciudad asediada por el bombardeo durante diez días seguidos, para acudir al deber de hijo y de hermano, y aun de esposo y padre, con el luto en el corazón y el libro escolar bajo el brazo.

Recuerda a Ricardo Gómez Robelo que en los campamentos revolucionarios traduce a Elizabeth Barret Browning. ¿Y qué leería él mismo durante la Decena Trágica? Si como Pascal, está seguro de que nosotros contenemos al universo por el espíritu, también rinde tributos pasajeros a las fuerzas terrenales, y por eso, en el segundo milenario del poeta latino, produce su "Discurso por Virgilio", ese bello texto que, en su primera versión, hermana abiertamente la reforma agraria del presidente Plutarco Elías Calles y la lectura de las Geórgicas. Allí Reyes es sincero al extremo:

Tomar partido es lo peor que podemos hacer. Es mucho más legítima la esperanza en "la raza cósmica" de Vasconcelos; la fe en "la cultura humana" de Waldo Frank. Adoptémoslo todo y tratemos de conciliario todo. Aquello en que no haya conciliación será equi- 
vocado y de ello podremos prescindir a la izquierda y a la derecha ${ }^{10}$.

Él lo repitió: "Todo lo sabemos entre todos", ¿por qué dividirse? El deseo de no tomar partido es algo más que escapismo o miedo a la violencia. Sí, y sobre eso el propio "Discurso por Virgilio" no deja duda, ha tomado el partido del Estado, lo que pretende es aportarle al Estado su certidumbre ("la cultura es una función unificadora') y comunicarle a la sociedad su horror a las banderías, que surge de la experiencia del intelectual en México, expulsado o burlado cada vez que toma partido. Y no es esto lo peor: la posición de los intelectuales ha fomentado desdichadamente al anti-intelectualismo que será muchas cosas (machismo, miedo y desprecio al conocimiento, pavor ante la idea de un pueblo alfabetizado), pero que responde también a una equivocada y funesta toma de partido de quienes encarnan el conocimiento. Por eso, la democracia será principio a la vez concreto y abstracto, y el eclecticismo elaborará sintéticamente la concordia.

Si válidos - dice en la que quizás es su frase más citada - de nuestro leve peso histórico y hasta de haber sido convidados al banquete de la civilización cuando ya la mesa estaba servida...

Reconoce la condición de periféricos. Para transformarla en ventaja, conviene el ideal clásico. Aquí su utopía conoce el límite y se le debe entender literalmente, por ser el momento más débil y más poderoso ideológica y utópicamente de la producción de Reyes, y que no es, aunque así lo parezca, postura demagógica. Reclama la posesión de Virgilio (de toda la cultura) y, sin revestirse de profeta, vaticina lo que no se dio ni podía darse, la vuelta al campo, el retorno a lo agrario presidido y no como metáfora, por la lectura de Virgilio: el orbe latino devuelve al hombre su lugar, en la Eneida se inicia todo sentimiento nacional, la lectura de Virgilio es fermento para la noción de Patria, dotar a los niños con Virgilio es alimentarlos con médulas de león, el espíritu de Virgilio parece iluminar el cuadro de nuestra política agraria y -el sueño fabril va en ascenso- nada tendría de extraño que se recomendara en las escuelas agrícolas - y de modo general en las escuelas primarias - la lectura de las Geórgicas para despertar en la mente de los niños la vocación del campo. Y concluye su strawberry fields forever:

10 "Discurso por Virgilio", $A R O C$, t. 11, p. 172. 
Sobre la comarca recién desgarrada por las guerras civiles, como alta predicación de concordia, de unidad y de amor al trabajo, ruedan las ondas cordiales de las Geórgicas ${ }^{11}$.

No es extraño que quien se sintió Eneas al salir en 1913 de México rumbo a Europa, elija a Virgilio para este sueño enloquecido, desde el punto de vista de la realidad agrícola y política de México en los años treintas. Pero así no sea Reyes un pensador político, tiene razón a su manera, ahora lo sabemos casi demasiado tarde. El problema no es inundar las escuelas con Virgilio, sino la humanización del medio rural y de los ideales clásicos. Reyes pide sin aspavientos y sin insistir en la modificación del proyecto triunfante de nación que se incluya al conocimiento, que se vea en los intelectuales no a un ornamento sino a la conciencia civilizadora y a la presencia de la moral. No se le hace caso ni en México ni en sitio alguno, y él, pasada la fiebre del "compromiso" de los treintas, se aleja de la gran prédica y de vez en vez insiste en la reformulación de la utopía. Ése es su gran alegato. O la función unificadora de la cultura o... y aquí se calla.

Las utopías de Reyes son obligadamente nacionalistas, y enunciadas sin convicción urgente, algo ajeno a su temperamento y al mínimo criterio de realidad. Él, a quien tantos llamaron descastado, quiere probar que la casta no radica en el apego sino en la amplitud de la visión del mundo. Hay que conocer, orientar, organizar la tradición (en una palabra, inventarla), y en esta religiosidad cultural que es principio moral, conviene imprimirle fuerza a los trabajos de una minoría de escritores y pensadores.

Y decir que todo esto no importa al pueblo - arguye defensivamente- es tan pueril como querer otra vez que la ciencia sea privilegio de una casta sacerdotal; como esperar que el pueblo aprenda sin tener maestros que lo enseñen; como pretender que el pueblo abandone las urgencias vitales para inventar por su cuenta la cultura; como soñar que las grandes orientaciones nacionales hayan de caer solas sobre la muchedumbre, desde las alturas de no sé qué fabuloso Sinaí, sin la obra de investigadores que consagran a buscarlas y a interrogarlas sus estudios, sus vigilias, su vida toda ${ }^{12}$.

Es conmovedor, por heroico, el esfuerzo de Alfonso Reyes. $\mathrm{Y}$ no deja de ser comprobación melancólica nuestra necesidad ac-

11 Ibid., p. 175.

12 Ibid., p. 160. 
tual de traducirlo, de ver en él un mucho mayor arraigo del que le supusimos, sólo que discreto, a la defensiva. Hoy sabemos que su mayor drama público no fue la muerte violenta de su padre sino la condición del escritor calificado de "apátrida" por el anti-intelectualismo, en un país juzgado "bárbaro" o "atrasado" por los criterios en que él creía. Reyes quiso asirse de lo nacional no como orientación intelectual sino en tanto principio de entendimiento de la realidad, y lo opuso frente al autoritarismo. Quiso hacer - con grave modestia y necesaria inmodestia - las veces de puente entre Occidente y México y mucho consiguió pese a la desmesura del intento, pero Occidente (lo que él así consideraba) apenas lo percibió. Era demasiado el peso de la arrogancia colonial, como se ve en la línea despreciativa que a su obra dedicó José Ortega y Gasset: "gestecillos de aldea". Quiso ser leído y sus obras completas resultaron un mausoleo poco accesible para el lector común que somos todos.

Mucho nos queda de esa "comedia de las equivocaciones". En el caso de Reyes, la prosa es proposición civilizadora en sí misma. La idea de Valéry que cita Cardoza: "La sintaxis es un don del alma", en Reyes se vuelve la incorporación del lector al proceso del pensamiento del escritor. Don Alfonso virtió una cultura general en un público particular, y quiso hacer de la claridad expresiva una función ciudadana. Todo, también, lo ignoramos entre todos, pero a la cultura de habla hispánica la enriqueció vastamente este prosista deslumbrante que facilitó el tránsito de lo eclesiástico a lo secular, al llevar a la práctica una idea: a la pérdida de la fe religiosa (o si no se quiere hablar de pérdida, a la integración de la fe en el mundo), la sustituye la edificación de perspectivas civilizadoras. Por eso don Alfonso habría hecho suya la oración de Milton en Paradise lost:

Tratemos de establecer qué fuerzas nos pueden dar nuestras ilusiones; y si no, qué resolución nuestra desesperanza. 